\title{
horvega
}

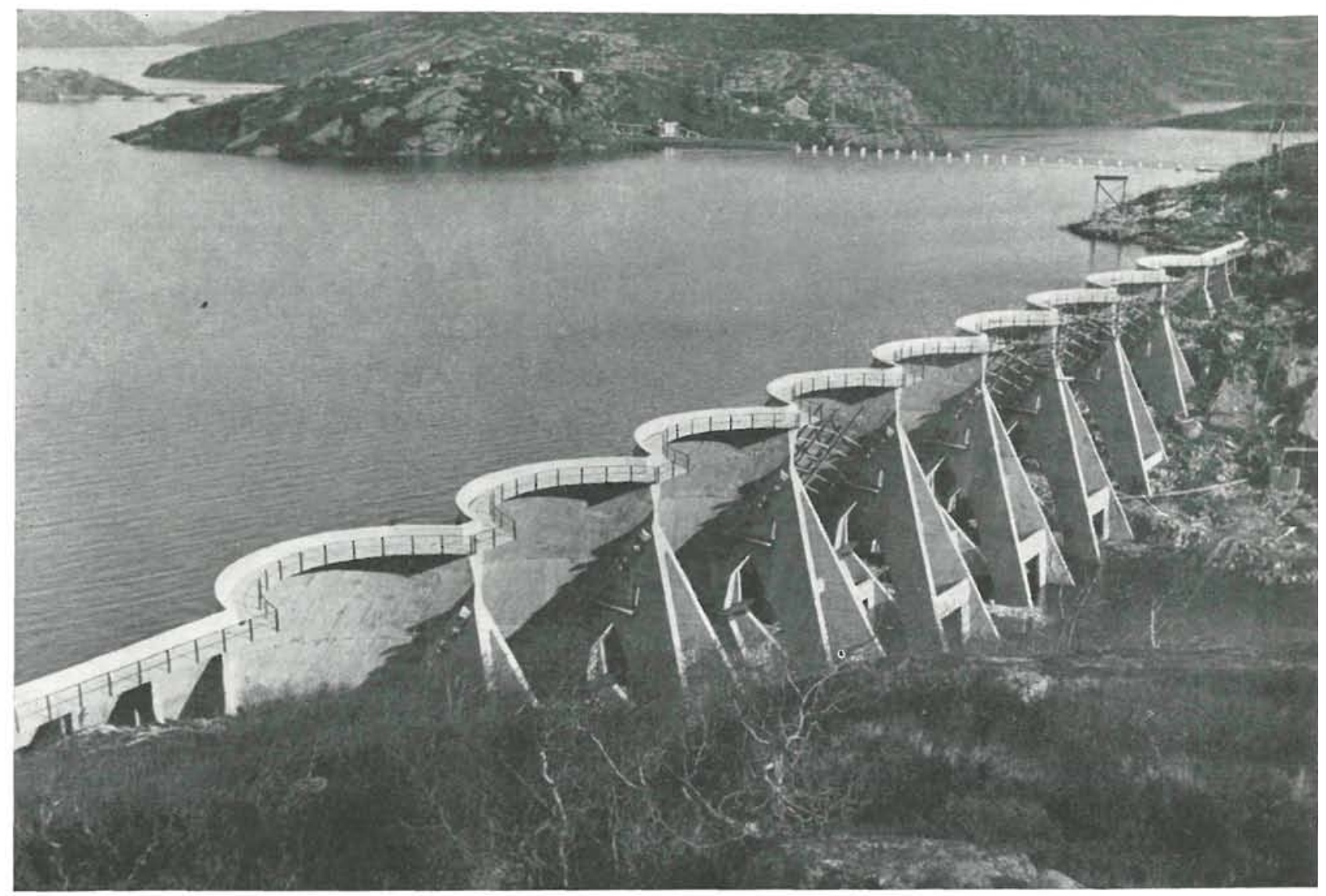

$531 \cdot 35$

\section{Oresas bóveda}

CHr. F. GRONER, ingeniero

En Noruega, durante los pasados cincuenta años, el desarrollo de los aprovechamientos hidroeléctricos ha sido un factor vital para la economía del país. La construcción de presas ha seguido un sendero diferente al que se practicó er otras naciones. Los lugares propios para el emplazamien to de estas presas se hallan en zonas de climas variables, y altitudes cuyas diferencias máximas sobre el nivel del mar es de unos $1.200 \mathrm{~m}$. Muchas de las presas tienen una estructura esbelta, de hormigón armado, cuyas razones se explican por las causas siguientes:

1) Como el transporte de materiales de construcción a las montañas es caro, y el período anual de trabajo en las partes altas sólo es de cincc a siete meses, la cantidad total de materiales que se han de transportar para la presa debe reducirse tanto como sea posible.

2) El agua de los lagos y ríos noruegos es ácida ( 5,6 a 6,7 p. p. m. de pH) y, excepcionalmente, pura. Por ello, la infiltración del agua a través de juntas y fisuras no presenta el aspecto de acarreo y taponamiento.

3) En un dique de pared delgada es relativamente fácil la localización de la pérdida y seguir su corriente hasta el lugar de origen. Esto es mucho más difícil en las construcciones pesadas, donde el agua puede tomar un camino intrazable al atravesar la presa.

Gracias a la presencia de valles angostos y de buena roca para cimientos, abundan los emplazamientos excelentes riara las presas bóveda en dicho país. La primera presa noruega de este tipo se construyó en 1930. Desde este año, se han construído muchas presas de esta clase que llegan hasta $50 \mathrm{~m}$ de altura y, actualmente, se está construyendo una que tiene 70 metros. 

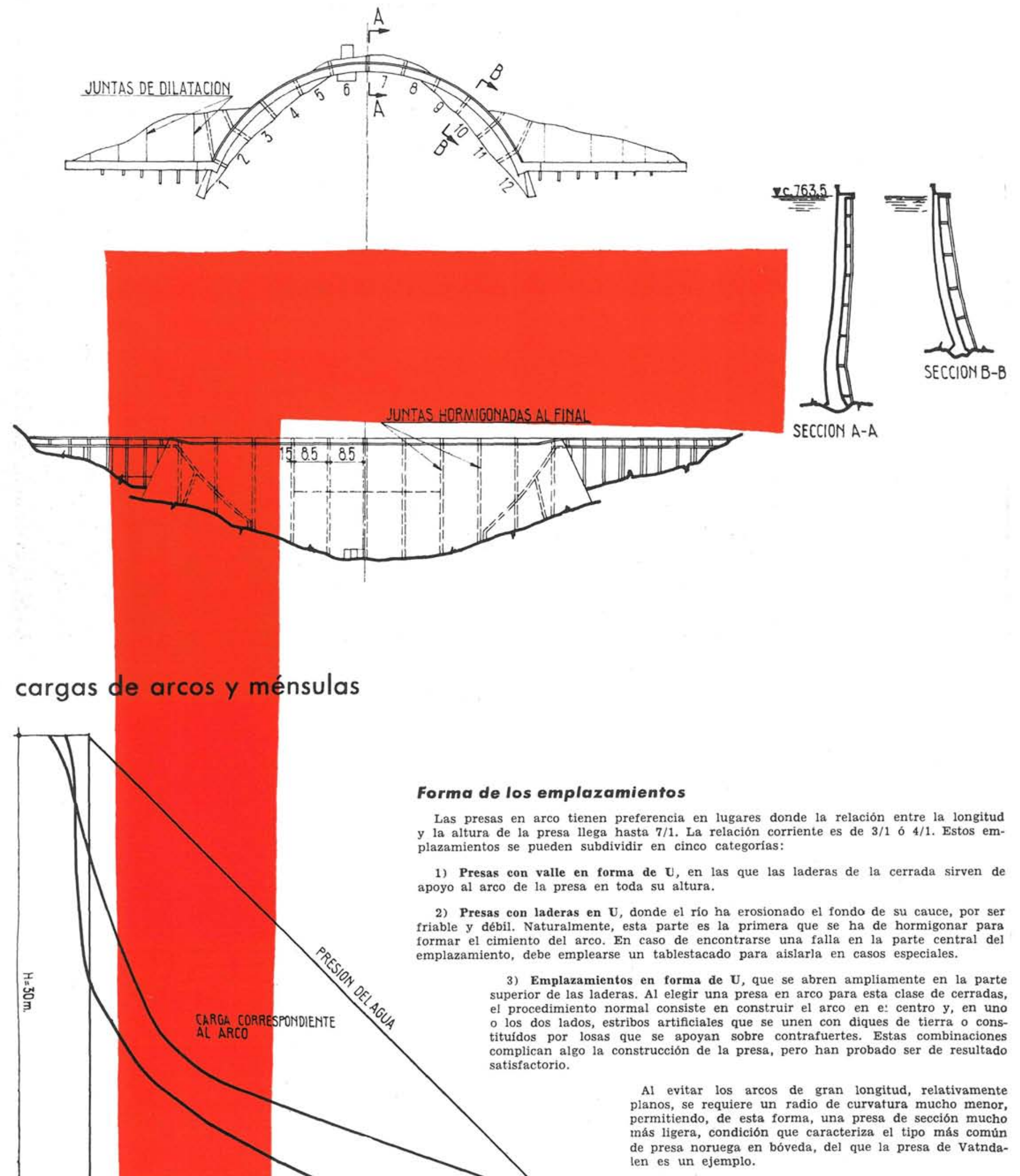

4) Emplazamiento en cañones o gargantas estrechas, caso no común en Noruega. 


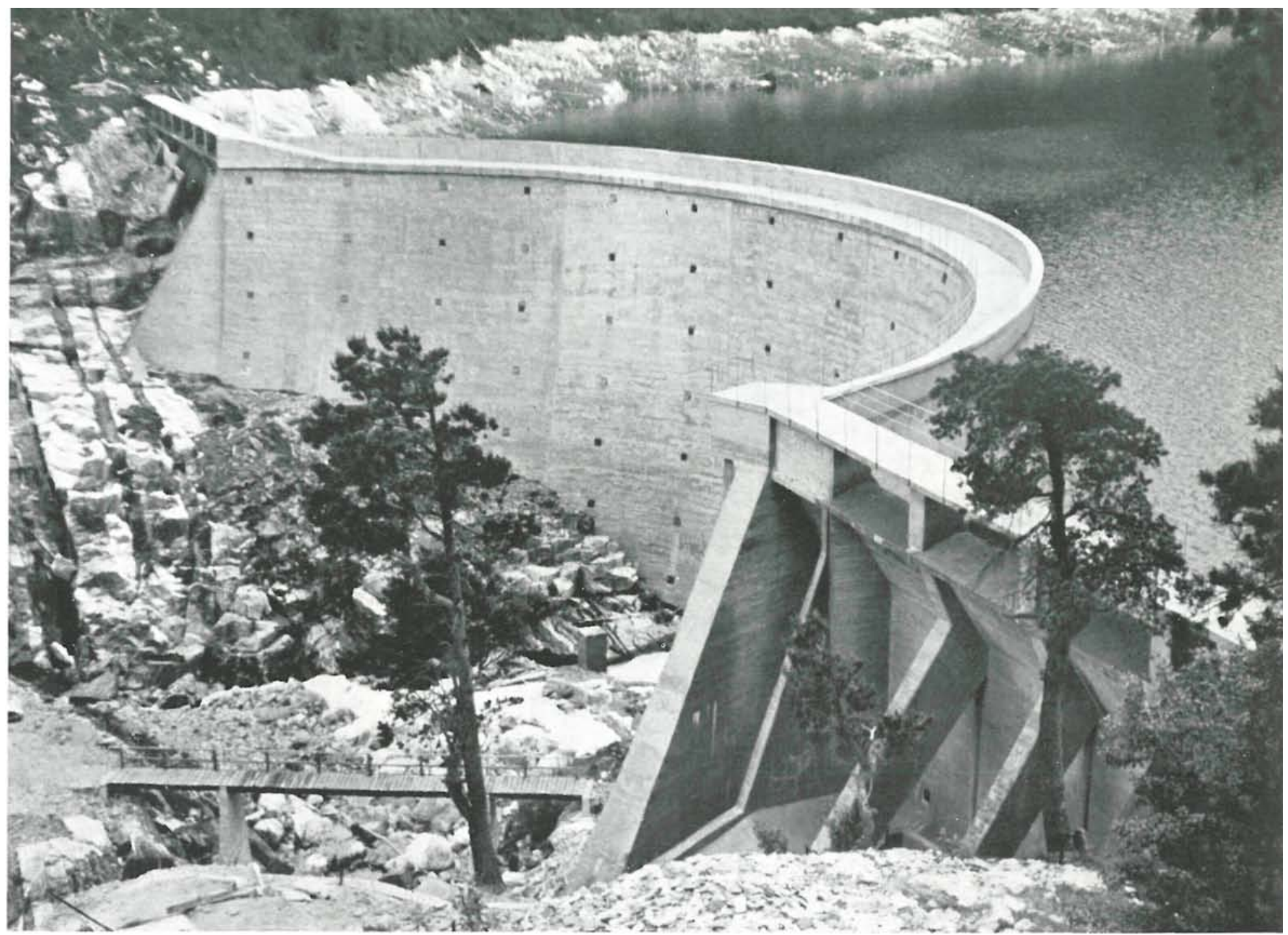

5) Emplazamientos en valles abiertos, bajos, donde se emplean presas de bóvedas múltiples. En esta clase de emplazamientos sólo se han construído tres presas de este tipo en Noruega, por lo que no se han tomado en consideración en este trabajo.

\section{Principios constructivos}

Las pequeñas presas bóveda se han proyectado, principalmente, siguiendo el principio de radio constante. El método de formas cilíndricas se ha reservado para el caso de pequeñas presas; pero al tratarse de presas mayores, el procedimiento seguido ha sido el de ángulo constante y radio variable.

En este caso de presas mayores, el método de cargas de prueba es el que corrientemente se emplea; para ello, se hace uso de una serie de elementos horizontales de arcos y sólo uno vertical o ménsula. En casos especiales, se calculan tres ménsulas. Corrientemente, el elemento vertical elegido no se le considera fijo en la base. La fijación en ésta quiere đecir que una desproporcionada gran parte de la carga del agua se supone que debe ser absorbida por el elemento vertical o ménsula. En una presa en arco, la mayor parte de la carga debe absorberse por el arco, es decir, que ésta ha de ser el soporte fundamental.

La carga correspondiente a la dirección horizontal y vertical de la presa Vantdalen se ha representado en la figura adjunta, en la que (A) corresponde al caso en que el elemento se supone fijo en su base; y (B), cuando éste ha sido supuesto articulado en la misma. En ciertos casos se forma una junta de construcción en la base, pero normalmente el arco se une directamente con la roca. En el paramento de aguas arriba no aparecen grietas nocivas.

La Dirección General de Obras Hidráulicas noruegas ha determinado que la tensión autorizada para el hormigón trabajando a compresión no debe exceder de $50 \mathrm{~kg} / \mathrm{cm}^{2} ;$ y el coeficiente de seguridad para pandeo, de 8 , La presa se ha proyectado para una variación de temperatura, cuando se halle vacia, de unos $20^{\circ} \mathrm{C}$ en coronación y $10^{\circ} \mathrm{C}$ en la base; y cuando se halle llena, para una variación de $10^{\circ} \mathrm{C}$ en la parte superior y $5^{\circ} \mathrm{C}$ en la base.

Generalmente la calidad de la roca de estribo es buena, a ex sepcíon de la parte central, que comprende el lecho actual del río, donde la roca puede ser con frecuencia más bien de calidad pobre. 
detalles constructivos
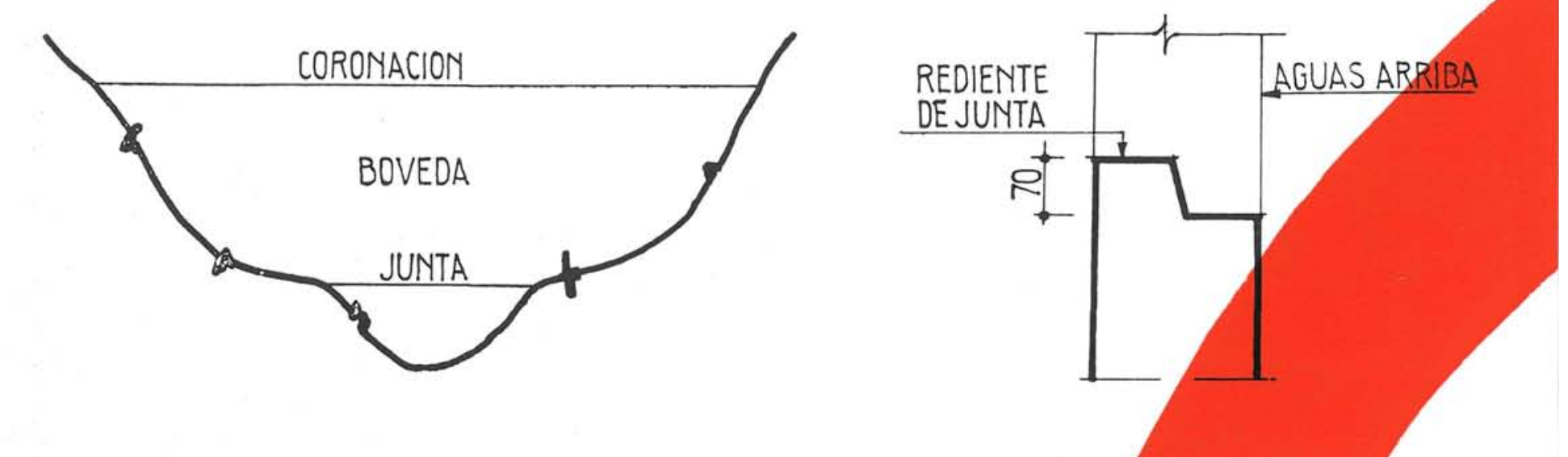

grietas y curvas granulométricas
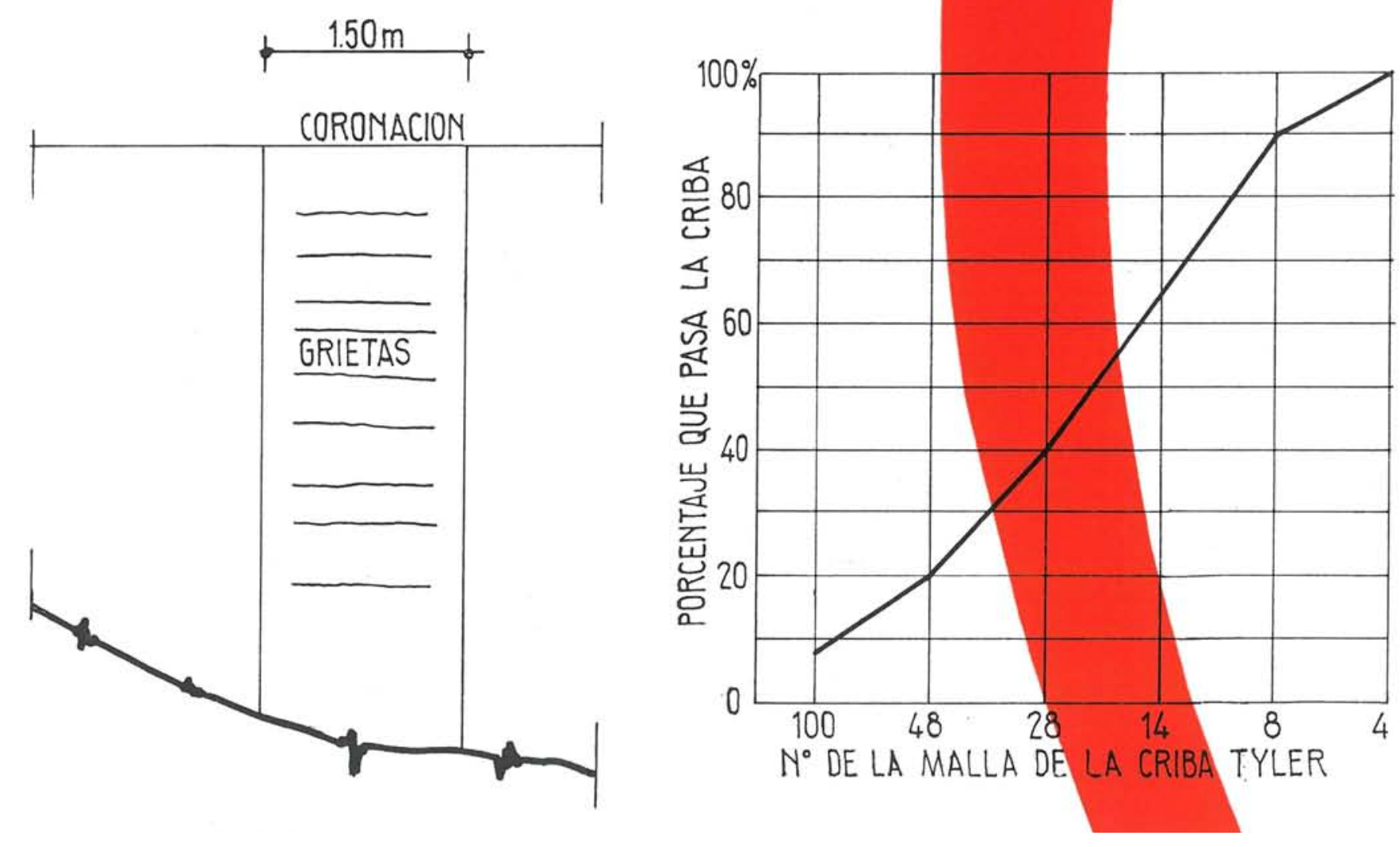


\section{presa juvann}

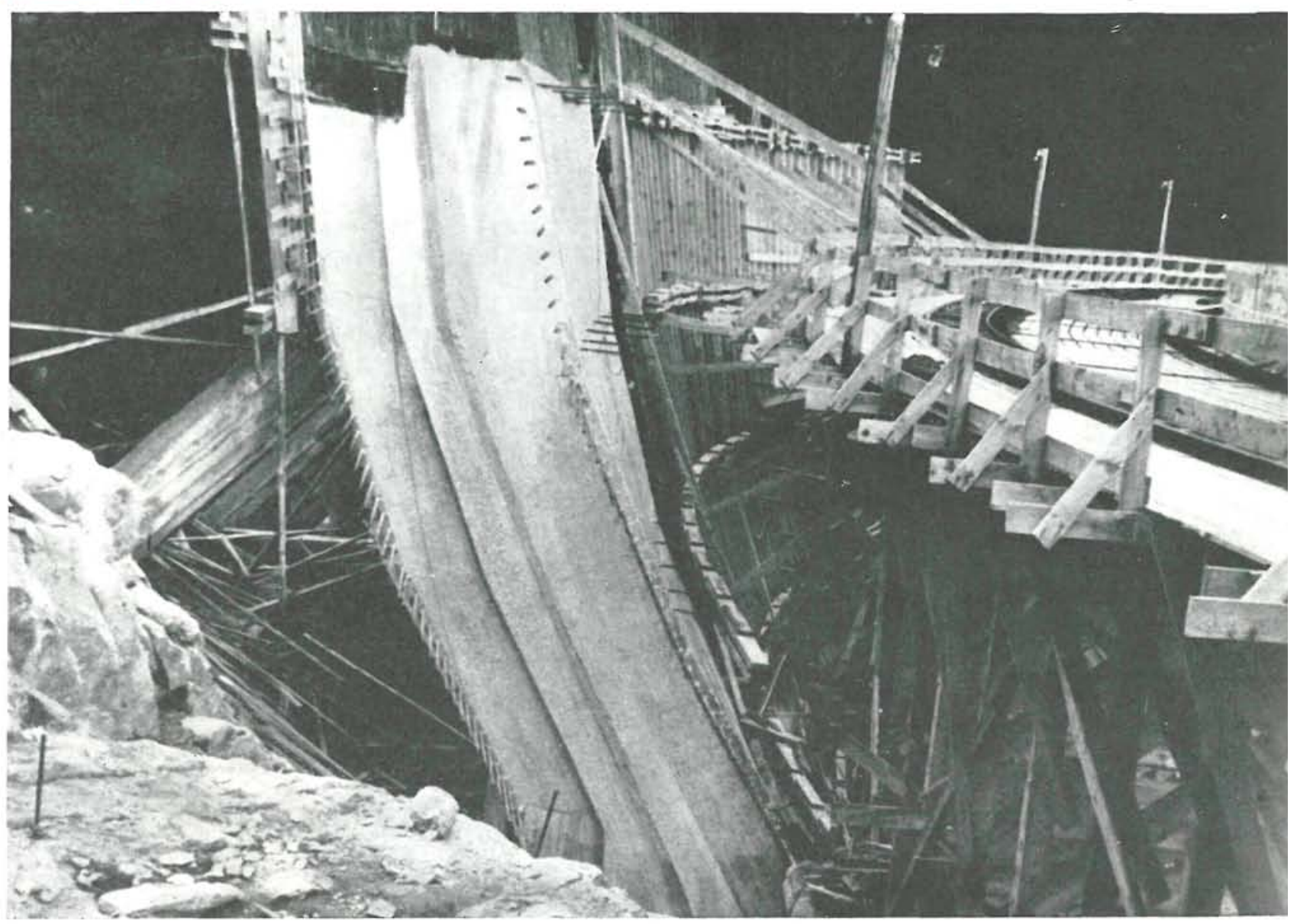

Las condiciones de la roca han exigido algunas inyecciones ocasionales, pero la base se suele inyectar después de terminar la presa y durante el período en que se llena el embalse. Cualquier fuga en la roca se puede localizar, pudiéndose inyectar para taponarla.

Las presas se hormigonan en bloques de unos $8,50 \mathrm{~m}$ de longitud. Entre los bloques se dejan espacios vacíos, con paredes dentadas, de $1,50 \mathrm{~m}$ de luz, que sirven como juntas de contracción, permaneciendo abiertos hasta la terminación del período de construcción. Cada uno de los bloques se ha calculado para resistir la presión máxima del viento. En el caso de arcos de ángulo constante existe una zona de ménsulas considerables en los cuartos puntos, empleándose columnas de hormigón armado como soportes provisionales para estos voladizos.

La reducción del número de juntas de una presa, disminuye el rỉesgo a la mínima posibilidad de infiltraciones. Cada bloque se hormigona continuamente desde la parte inferior a la superior, a excepción del caso en que la altura del bloque es superior a $\operatorname{los} 25 \mathrm{~m}$, siempre que el hormigonado se divida con una junta horizontal de construcción, como se puede apreciar en la figura. En ninguna de estas juntas de retracción o construcción se emplean bandas de sellado. Todas las superficies se repican o se les da una aspereza completa, lavando después antes de continuar el hormigonado. Para evitar las infiltraciones se toman grandes precauciones y cuidados.

\section{Colocación del hormigón}

El hormigón empleado es, normalmente, de $350-400 \mathrm{~kg}$ de cemento por metro cúbico. La resistencia exigida con probetas cilíndricas es de $232 \mathrm{~kg} / \mathrm{cm}^{2}$ a los veintiocho días. A la dosificación correcta de arena se le concede gran importancia. En la medida de lo posible, la curva granulométrica de la arena será similar a la que se puede apreciar en la figura.

Siempre que es posible, se usa grava y arena natural; pero es frecuente el empleo de grava machacada y finos molidos. Al hormigón se le añade un agente aireante que incorpora un volumen máximo de aire del 3 al $4 \%$. Durante el hormigonado, la pasta se vibra directamente. Los bloques se hormigonan a razón de 30 a 50 centímetros de espesor de tongada por hora; proporcion baja, pero necesaria para evitar un aumento de temperatura durante la construcción. Las juntas de contracción se hormigonan a razón de $30 \mathrm{~cm}$ por hora. Tiene extrema importancia que esta proporción no se exceda, con objeto de evitar grietas debidas al calor químico desarrollado durante el fraguado del hormigón. Las juntas de contracción se hormigonan cuando la temperatura ambiente oscila alrededor de $0^{\circ} \mathrm{C}$, y después de, por lo menos, tres o cuatro meses de haber hormigonado los bloques adyacentes. Durante este período de tiempo, todo el hormigón ha experimentado su contracción como resultado de la retracción y caída de la temperatura. De hormigonar las juntas de retracción con una temperatura ambiente muy elevada, o si el hormigonado se ha llevado a cabo con excesiva rapidez, bastante cantidad ciel calor obra como causa de grietas horizontales (este fenómeno está representado en la figura).

Los bloques adyacentes suelen estar suficientemente fríos para el hormigonado del espacio entre bloques, o junta de contracción, cuando la temperatura descienda a $9^{\circ} \mathrm{C}$. Tiene su importancia que los encofrados cierren bien, con el objeto de evitar que la superficie del hormigón se enfríe por debajo del punto de congelación. 


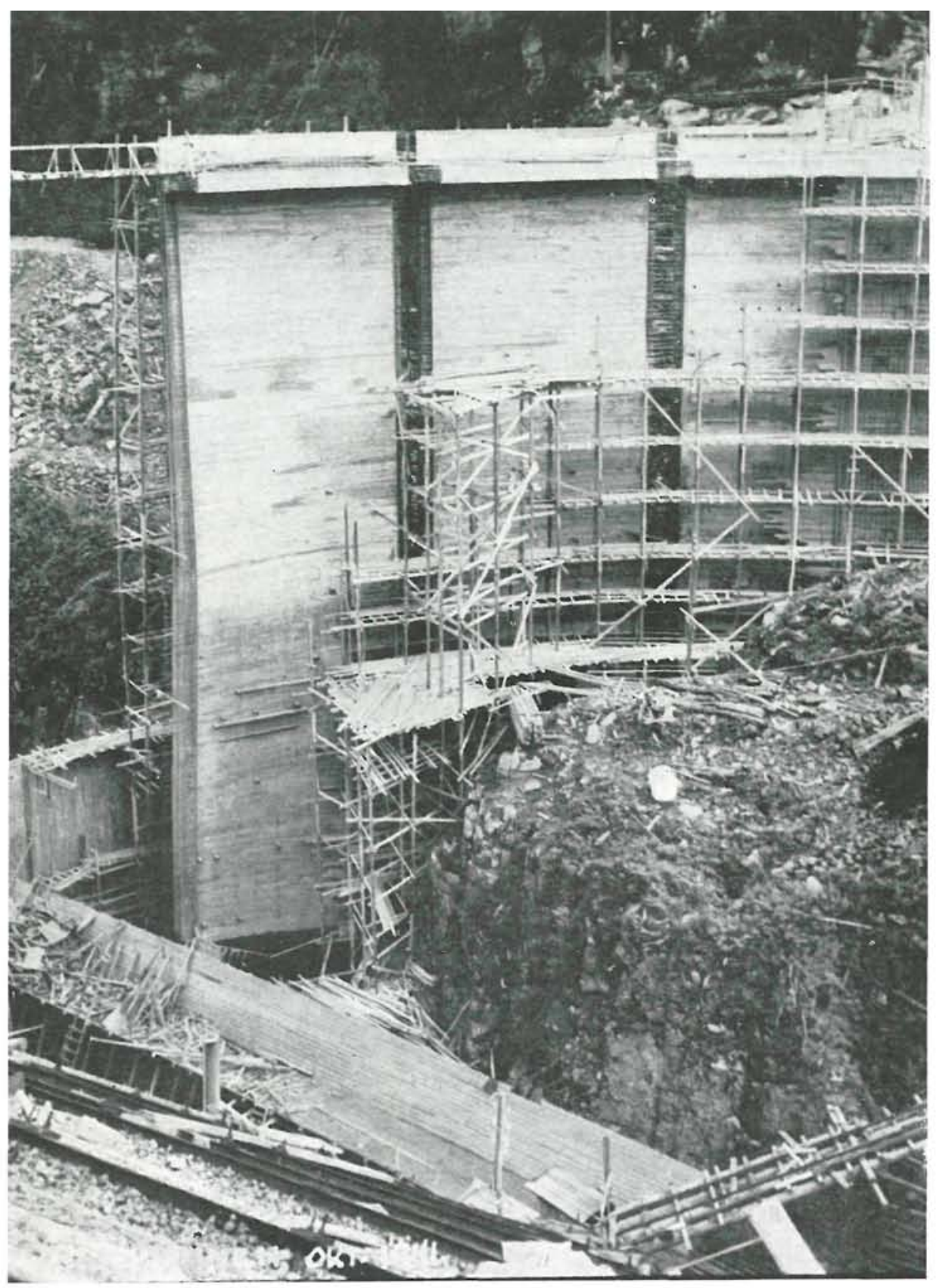

presa Langli

Antes de empezar el hormigonado es frecuente el empleo de una elipo de calefacción se prefiere el empleo de la electricidad.

Si la temperatura se halla por debajo del punto de congelación durante un largo periodo de tiempo, debe aislarse el encofrado con un recinto móvil de unos 4 a $5 \mathrm{~m}$ de altura sobre la superficie de la roca en la proximidad de la junta de retracción para calentar la parte más baja de la junta. Cuando ha empezado el hormigonado, la temperatura del fraguado mantiene el ambiente y superficie de los labios de la junta a una temperatura superior a la del punto de congelación. A medida que avanza el hormigonado, se va elevando el tejado del recinto móvil de protección.

Para evitar las juntas involuntarias, debe colocarse el hormigon en os encofrados por lo menos tres veces por hora. Durante el hormigonado de las juntas de retracción, se emplean vibradores que se llevan a las partes angulosas y caras de contacto.

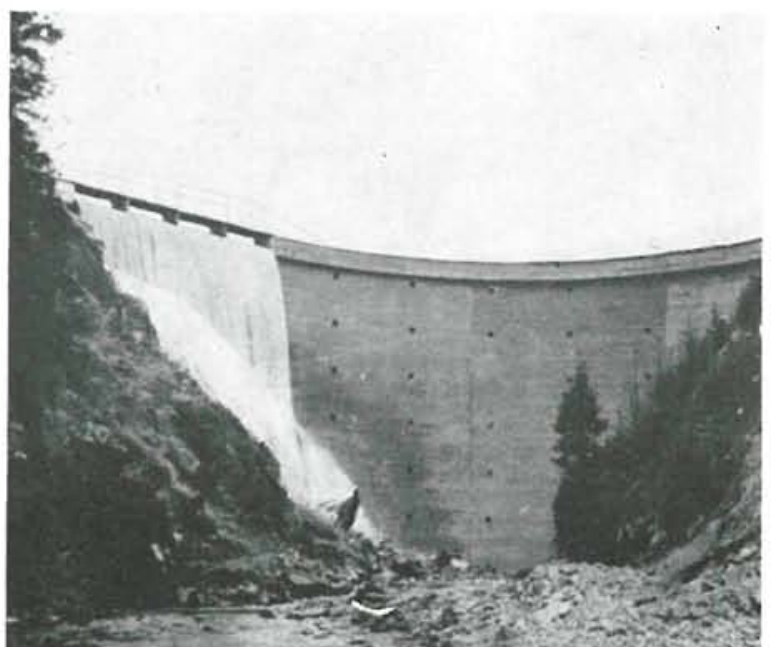




\section{Temperafura}

En el interior de las juntas de retracción, o espacios entre bloques, la temperatura varía mucho. En el núcleo central de la junta, la temperatura es más elevada que en las zonas de contacto con los labios fríos. El autor ccntroló personalmente la temperatura en una de estas juntas, de una presa en arco de $30 \mathrm{~m}$ de altura, hormigonada con una temperatura de hasta $12^{\circ} \mathrm{C}$, en los meses de noviembre y diciembre, encontrando que ésta era superior a la correspondiente al punto de congelación.

En dos de las figuras, referentes a la presa Vatndalen, se puede apreciar alguna de las de temperatura en las juntas de retracción.

Cuando se esperan temperaturas más elevadas, debido al mayor espesor de los arcos, se emplea una refrigeración artificial, que consiste en la instalación de tubos con circulación de agua ción

En una de las figuras se han representado las temperaturas en las juntas utilizando una refrigeración artificial. La dosificación del hormigón en cemento fué de $350 \mathrm{~kg}$ por metro cúbico de hormigón. Al relacionar estas curvas de temperatura con la curva A correspondiente a hormigón de igua espesor $\sin$ refrigeración artificial, el efecto de la refrigeración se ve claramente. Tiene importancia la reducción de tensiones debidas a descensos de temperatura durante el invierno en el aico, así como la reducción de la formación de grietas horizontales en las iuntas de retracción después de haber hormigonado.

El agua para la refrigeración se tomó del río, a una temperatura de $2^{\circ}$ a $3^{\circ} \mathrm{C}$, y después de salir del sistema de refrigeración esta temperatura se elevỏ de $4^{\circ}$ a $5^{\circ} \mathrm{C}$

En una de las figuras se pueden ver las curvas de temperatura de zonas refrigeradas artificialmente, La curva $B$ corresponde a un hormigonado con sistema refrigerante; y la $\mathrm{A}$, a otro en el que no se ha refrigerado.

En ciertos casos, la parte central de la presa se ha hormigonado sin juntas de retracción; pero, como regla general, esto ha dado lugar a cierto numero de pequeñas grietas horizontales, debido a la gran diferencia de temperatura entre la parte central y los lados. Estas mismas condiciones prevalecen cuando se hormigona contra el paramento vertical de un banco de roca. En este caso se desarrollan grietas ligeramente diagonales contra el paramiento de la roca, debido a la diferencia de temperatura. En la base de la presa deben evitarse cambios bruscos de altura; esto obliga a seguir una línea de nivel, ya que, de lo contrario, la experiencia ha demostrado que se desarrollan grietas de dirección diagonal las figuras.
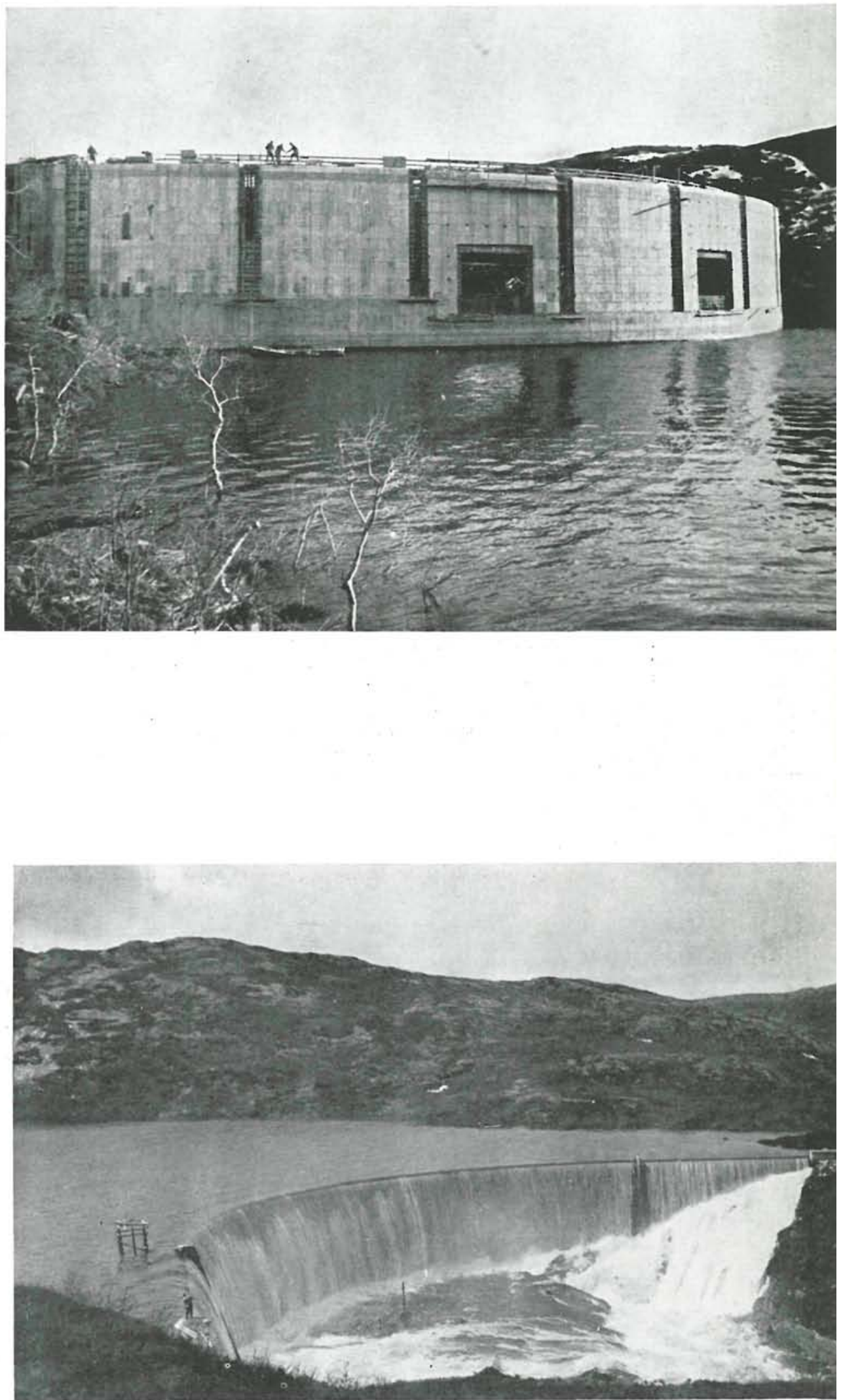

presa Skjerkavann 


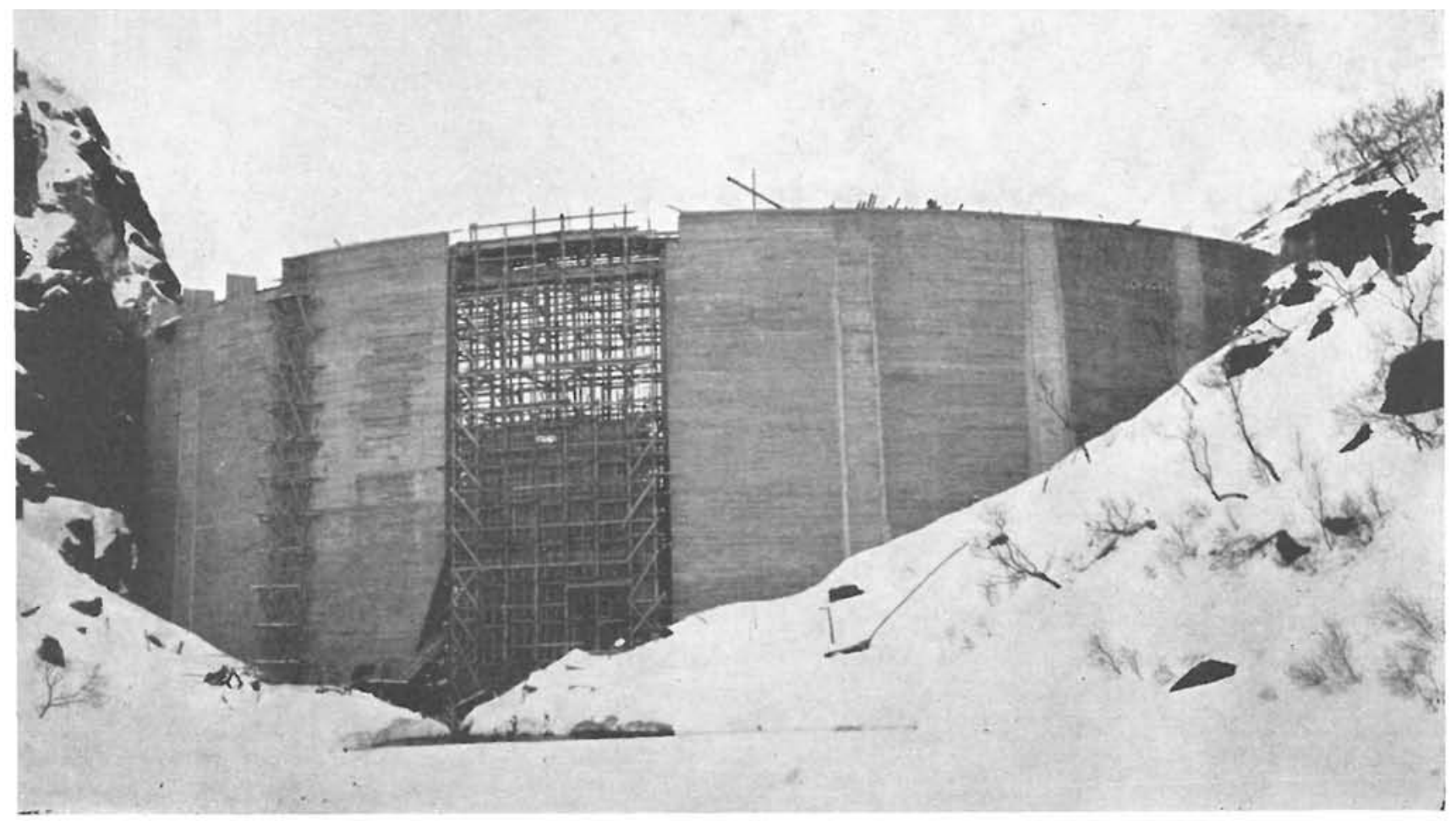

\section{Encofrados}

Los encofrados deben quitarse antes de que la temperatura del hormigón haya caído aproximadamente a la del ambiente. Esta forma de proceder evitará la fisu ración debida a que la cara aún caliente del hormigón se halla expuesta a un ambiente más frío. El tratamien to de curado debe mantenerse, por lo menos, tres semanas después de haber hormigonado.

Los encofrados se fijan en obra por medio de pernos que, en el paramento de aguas arriba, van ajustados en unos manguitos soldados para evitar infiltraciones a lo largo de dichos pernos. Este tipo de fijación con pernos ha dado buenos resultados en las partes principales, pero no se ha permitido su empleo en las juntas de retracción.

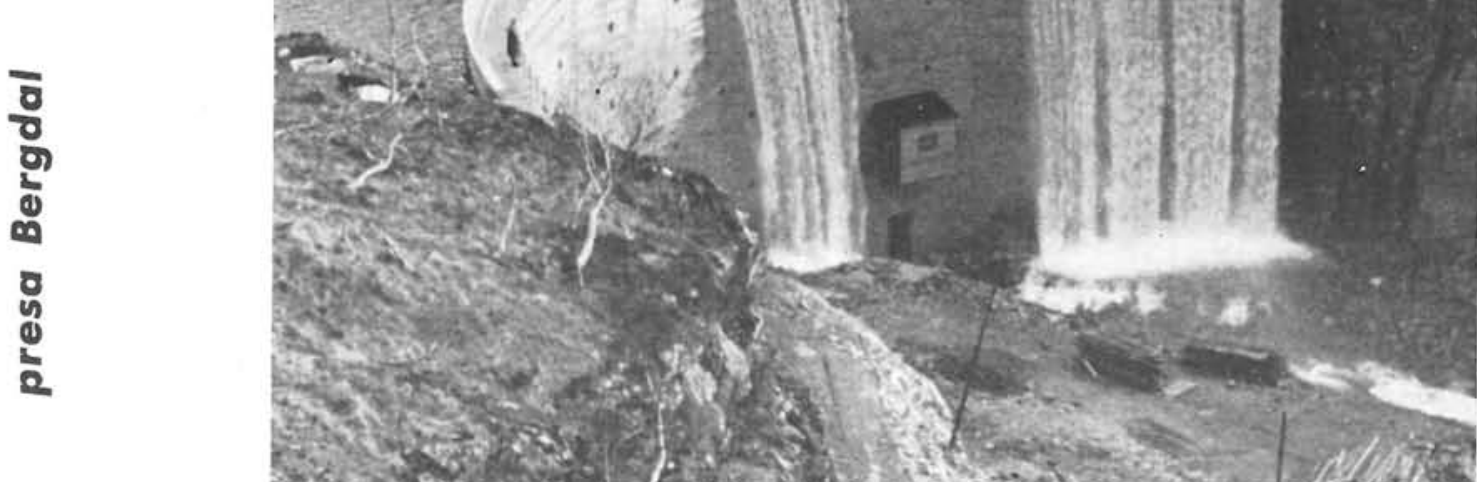



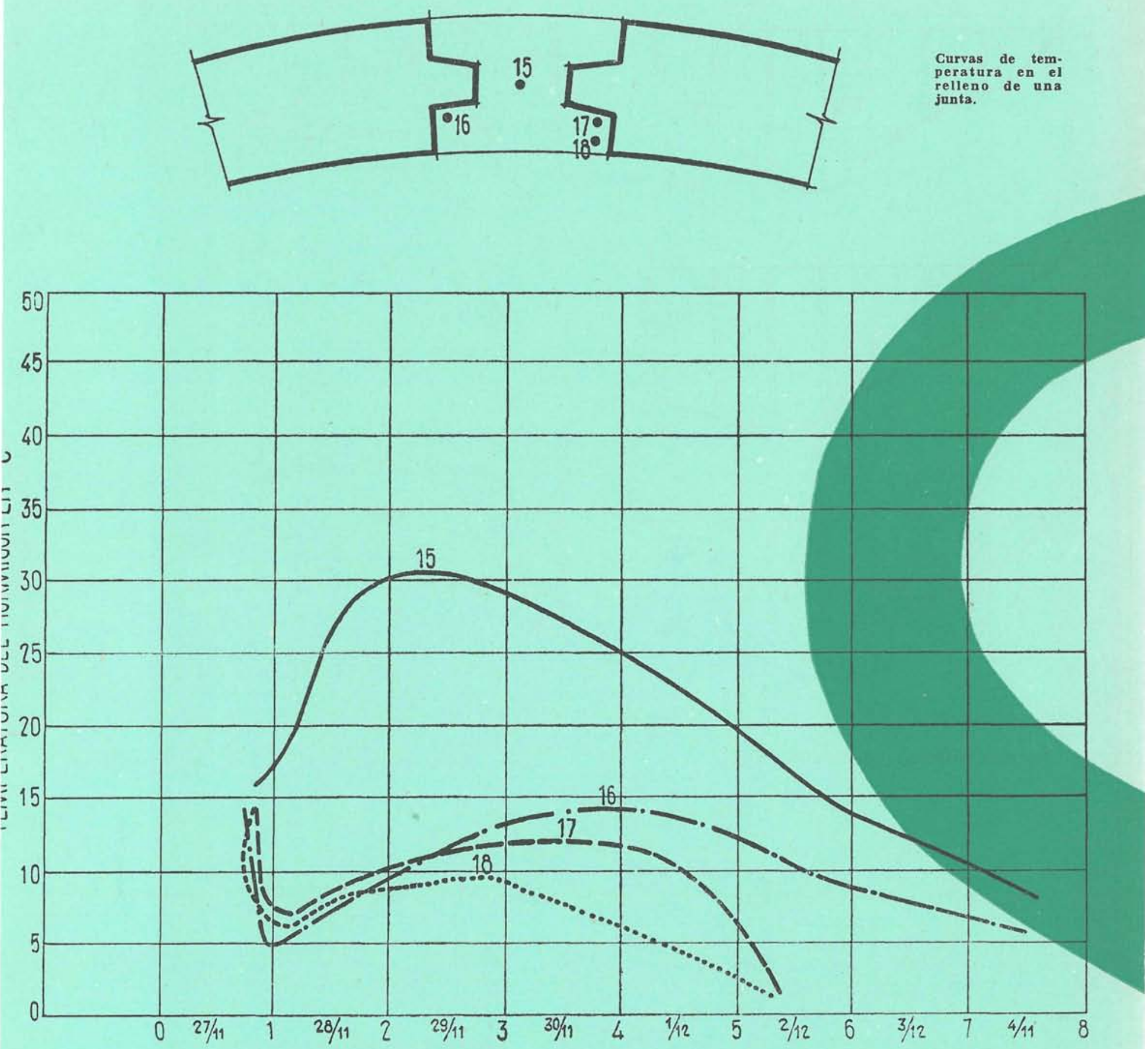

Para desencofrar basta destornillar estos pernos, retirar los encofrados, limpiar el hueco de $5 \mathrm{~cm}$ de profundidad que dejan y rellenarlo con mortero.

\section{Panfalla aislante}

Debido al poco espesor de estas presas, siempre queda un estado húmedo en el hormigón, donde el agua libre se acerca hasta el paramento de aguas abajo, por muy compacto y bien colocado que haya sido el hormigón. En el invierno, con bajas temperaturas, aparecerán con el tiempo desperfectos provocados por la helada. Para evitar esto se construyen muros, en forma de pantalla, en el paramento de aguas abajo, que tienen por objeto aislar dicho paramento contra los efectos de temperaturas bajas. Estas pantallas, normalmente de hormigón armado, de 10 a $15 \mathrm{~cm}$ de espesor, se suelen colocar, por 10 menos, a unos $80 \mathrm{~cm}$ del paramento de aguas abajo (ver secciones A-A y B-B de la adjunta figura).

Esta pantalla aislante se soporta por medio de pequeños pilares apoyados en el paramento y espaciados a $4 \mathrm{~m}$, tanto en el sentido vertical como horizontalmente. Entre los pilares se monta una 

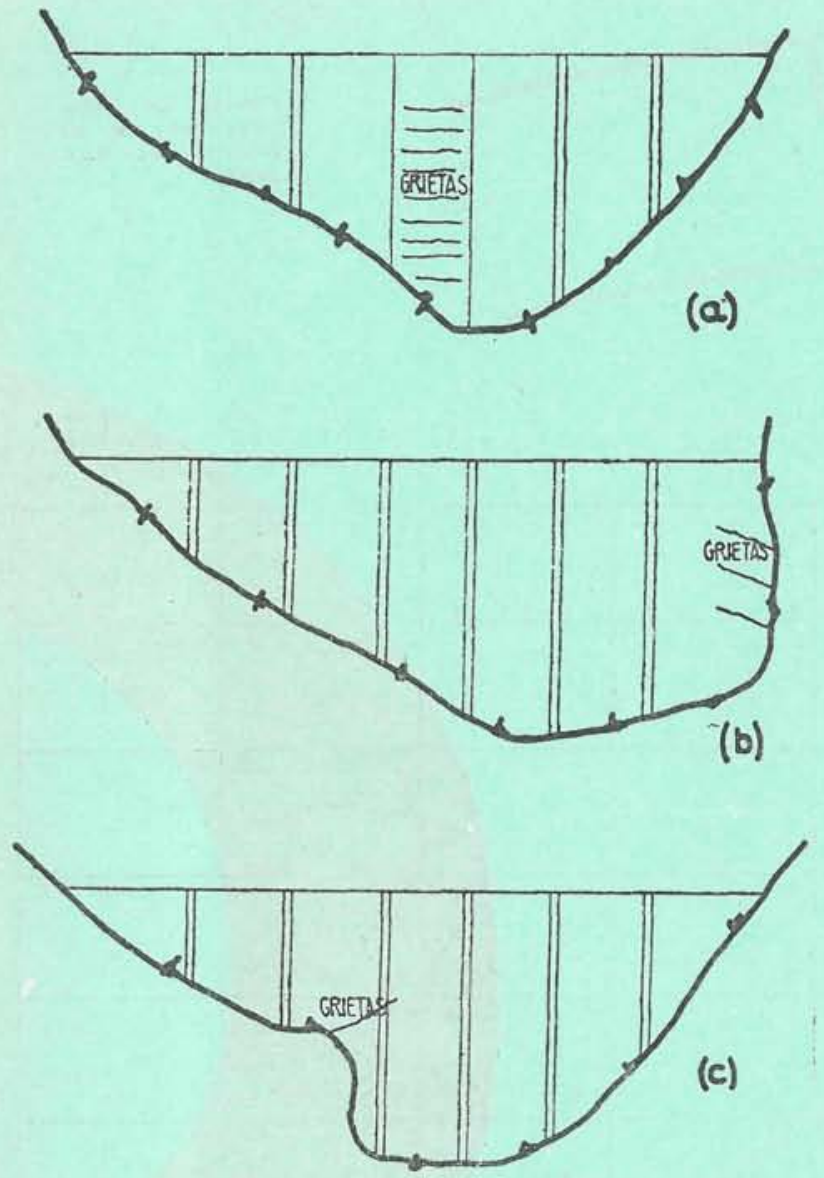

Tres tipos distintos de aparición de grietas.
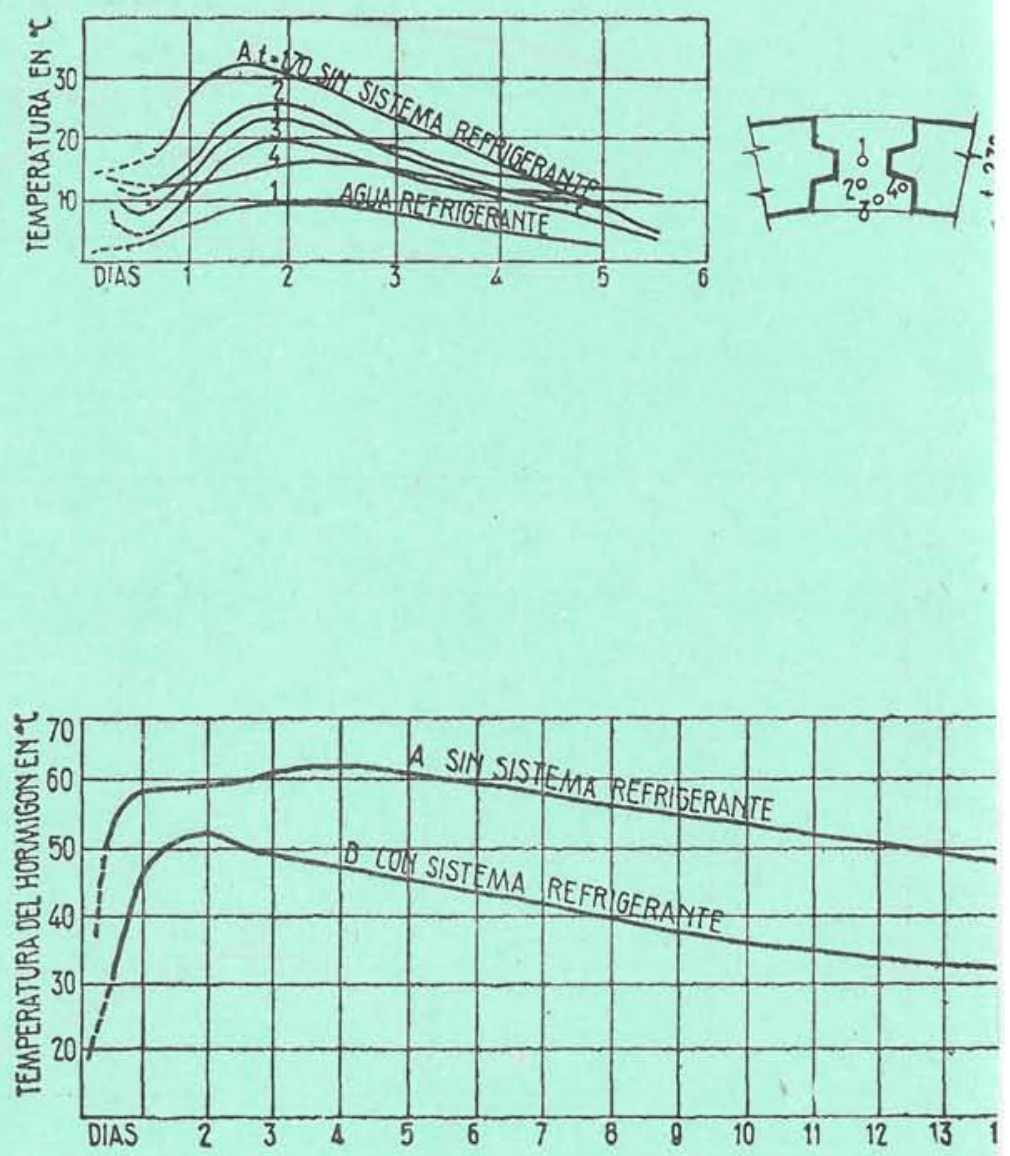

Curvas de temperatura, con y sin sistema refrigerante. pasarela, la cual permite la inspección del paramento. La pantalla no posee por si sola grandes propiedades aislantes; su principal objeto es el de proporcionar un ambiente de aire en calma contra el paramento de aguas abajo. Como resultado de todo esto, la temperatura de la presa permanecerá, durante el invierno, por encima del punto de congelación. La temperatura más baja observada detrás de estas pantallas aislantes ha sido de unos $-7^{\circ} \mathrm{C}$, incluso con temperaturas externas de hasta $-30^{\circ} \mathrm{C}$. Algunas veces estas pantallas se construyen con placas de madera contrachapada convenientemente impregnada, y se dejan ventanas, formando una cámara que algunas veces permite se caldee el aire entre el paramento y la pantalla aislante.

Las presas bóveda noruegas más antiguas tienen ya veinticinco años de existencia, sin que se haya podido observar hasta la fecha ningún desperfecto de importancia, Sin embargo, sin pantalla aislante, no parece se pueda dudar de la presencia de desperfectos debidos a la helada. Esto ha sido claramente demostrado en un número de pequeñas tomas, en las cuales, por no considerarlo necesario, no se había previsto aislante alguno. No es solamente la baja temperatura la que da lugar a desperfectos debidos a la helada. En la costa, donde la temperatura invernal es relativamente más elevada, los desperfectos debidos a la helada tienen su causa en los repetidos ciclos de hielo y deshielo durante la estación.

Los enlucidos de cemento solamente se aplican en la coronación de los vertederos, ya que la experiencia ha demostrado que estos enlucidos en cualquier otra parte de la presa no dan resultados sa- tisfactorios en un clima frfo. La experiencia lograda en otros tipos de construcciones hidráulicas, nos lleva a la conclusión de que el hormigón enlucido con mortero de cemento raramente da un resultado satisfactorio.

\section{Presas de bóvedas múltiples}

Este tipo de presa es una combinación entre las láminas en bóveda y las pantallas soportadas con contrafuertes.

La presa de bóvedas múltiples está indicada en las cerradas de gran luz, en las que la presa bóveda no es económicamente ventajosa, y donde la altura adquiere tal importancia que las presas de láminas apoyadas sobre contrafuertes son antieconómicas.

Resumiendo, las presas bóveda noruegas se construyen como estructuras ligeras de hormigón armado. En su construcción aparece, relativamente, un reducido número de juntas de construcción, juntas cuyos labios tienen forma dentada para evitar infiltraciones. Los paramentos de aguas abajo se protegen con pantallas aislantes para reducir los efectos nocivos de la helada. La experiencia noruega obtenida en la construcción de presas bóveda de hormigón armado ha sido excelente, y se ha llegado a la conclusión que estas presas, cuando su emplazamiento es apropiado, son superiores a las de otros tipos por su coeficiente de seguridad y por su correcta distribución de fuerzas, que le proporcionan una estabilidad perfecta. 